\title{
LA ESGRIMA CONVERSACIONAL: ENTRE LA TRADICIÓN DISCURSIVA Y LA TRADICIÓN POPULAR VERBAL ${ }^{*}$
}

\author{
CONVERSATIONAL \\ FENCING: BETWEEN \\ DISCOURSE \\ TRADITION AND \\ POPULAR VERBAL \\ USAGE
}


El presente artículo define la esgrima conversacional como una tradición discursiva que aparece en la copla folklórica, la literatura y el cine mexicano en la primera mitad del siglo xx. Tal tradición discursiva es atravesada por una tradición verbal popular que abreva del refrán, del albur y de otros usos indirectos del lenguaje. Pragmáticamente, la esgrima conversacional es evocada en una situación en la que los hablantes tienen una relación simétrica o de cercanía y están dispuestos a una interacción verbal en la que el tono de afrenta o donaire prevalece. Esta tradición discursiva respondería a la búsqueda de un triunfo simbólico que garantiza la subsistencia social, pero a su vez es parte de un legado histórico e idiomático del español de México.

Palabras Clave: tradición discursiva, tradición verbal popular, esgrima conversacional

The article defines conversational fencing as a discursive tradition appearing in the folkloric song, literature, and Mexican film in the first half of the twentieth century. Such discourse is intersected by a popular verbal tradition that contains proverbs, word games and other indirect uses of language. Conversational fencing is pragmatically evocated in a situation in which the speakers have a symmetrical or close relationship, and are willing to have a verbal interaction with offensive-joking and a sharp tone. This discursive tradition would answer to the search of a symbolic victory that warranting social survival but at the same time is part of the idiomatic and historic legacy of the Mexican-Spanish language.

KeYwORDs: discursive tradition, popular verbal tradition, conversational fencing

FECHA DE RECEPCIÓN: 05/05/2016

FECHA DE ACEPTACIÓN: 27/06/2016 


\section{LA ESGRIMA CONVERSACIONAL: ENTRE LA TRADICIÓN DISCURSIVA Y LA TRADICIÓN POPULAR VERBAL ${ }^{1}$}

\section{CONVERSATIONAL FENCING: BETWEEN DISCOURSE TRADITION AND POPULAR VERBAL USAGE}

Patricia Córdova

Universidad de Guadalajara

\section{Tradición verbal y tradición discursiva}

Es posible que cuando los individuos no alcanzan una soberanía mínima sobre los hechos de su vida cotidiana, el lenguaje aparezca como medio liberador con el que se encausa una opresión latente. También es posible que, al margen de la soberanía u opresión cotidiana, la creatividad lingüística acontezca como una expresión más de la inventiva de hablantes desenvueltos. Sucedería así con el juego de palabras que Lope Blanch (1989) encontró como característico del habla popular de la ciudad de México en la segunda mitad del siglo pasado, y que incluye expresiones como "Nos vemos por Acatlán" por "nos vemos por acá"; o "voy al otro Laredo", por "voy a otro lado"; o "Está en Cuernavaca" por "Está encuerado"; "glorieta” por "Gloria”; entre muchas más.

\footnotetext{
${ }^{1}$ Agradezco la atenta lectura y comentarios realizados por Gerardo Gutiérrez Cham y Jorge Martín Gómez Bocanegra.
} 
Sin embargo, como Lope Blanch reconoce, estos juegos lingüísticos también son característicos del habla popular de otros países. Basta revisar el hablar de germanía español, el lunfardo argentino, o la replana de Perú, según analiza Luis Fernando Lara (2011), para percatarnos de que la metáfora o la inversión son algunos juegos lingüísticos con los que se da forma a estas jergas. La productividad derivativa y composicional que se manifiesta en la creación léxica y fraseológica dan fe de la energía creativa con que el habla popular de cualquier comunidad lingüística se forma. ${ }^{2}$

Más recientemente, Lara ha explicado tal tendencia productiva como parte de las tradiciones verbales populares que constituyen

(...) la espontaneidad de la vida diaria y de las relaciones grupales e individuales, se transmiten sobre todo en la conversación, en los diálogos inmediatos en los barrios, en los pueblos, en las ciudades; tienen sus raíces en la misma historia de la lengua, a la que también nutren, pero proceden de las prácticas espontáneas del hablar y se aclimatan en las culturas locales, de las que toman su variedad y su

\footnotetext{
${ }^{2}$ Luis Fernando Lara (2012) va más allá que Lope Blanch y presenta no sólo un inventario de expresiones, sino una tipología de los recursos que se utilizan en el habla popular para formar sus tradiciones verbales. Los recursos son: 1) Se usa la raíz de una palabra y se modifica el final de la palabra, como en "servilleta" por servidor. 2) Se conserva el final de la palabra base y se modifica el comienzo, como en "Featriz" por Beatriz. 3) Fórmulas rimadas consonantes, asonantes o aliteradas, como en "iguanas ranas" por igual. 4) Expresiones complejas en las que se sustituye la palabra base, como en "a Wilson" por a huevo. 5) Eufemismos por conservación de raíz, como en "está cañón” por está cabrón. 6) Metáforas, como la Pelona por la muerte. 7) Formaciones neológicas a base de una raíz reconocible y adición de palabra, como en "miercocteles" por miércoles. 8) Apócopes y habla revesada, como "bici" por bicicleta; o "choga" por gacho.
} 
colorido; no son exclusivas del analfabetismo o de la falta de educación formal, como a veces se piensa, sino que son tradiciones del diálogo entre personas, cualquiera que sea su condición social" (énfasis mío) (Lara, 2012: 53).

Como puede observarse, Lara amplía el espectro de lo popular, no lo considera característico o exclusivo de hablantes con baja o nula instrucción educativa, como lo han hecho otros autores (Arjona Iglesias, 2004: 33), sino que es popular porque corresponde a una tradición de diálogo, del hablar en acción, al margen de la condición social de los hablantes. Acto seguido, tipifica expresiones mexicanas de acuerdo a ocho esquemas de producción ${ }^{3}$ cuyos ejemplos corroboran el solapamiento léxico que ha sucedido entre el caló mexicano, la germanía española, el habla del pachuco (Lara, 1992) y lo que hoy podríamos considerar el hablar popular mexicano, ${ }^{4}$ considerando lo popular según la acep-

\footnotetext{
${ }^{3}$ Véanse los esquemas en la nota anterior.

${ }^{4}$ Lara ha mostrado que "(...) la jerga de los pachucos forma parte del habla popular mexicana. No hay indicios de que se trate de un fenómeno dialectal particular (ni del suroeste de los Estados Unidos, ni del norte de México), ni de un fenómeno rural”. (1992: 86). El impacto de este hallazgo en la investigación lingüística mexicana es muy importante porque, entre otras cosas, significaría que es posible considerar narrativas literarias norteñas, que contienen un alto grado de lenguaje propio del hablar cotidiano, como muestras idiomáticas del hablar popular mexicano. Así cuando analizamos narrativas como las de Élmer Mendoza, quien creció en la Col Pop en Culiacán y quien despliega prodigiosamente, a través de sus personajes, el hablar propio de una zona de la que ha emergido un nuevo émulo social: el narcotraficante, nos encontramos frente a giros de un hablar sinaloense que, en realidad, acoge variantes regionales, de spanglish, de germanía, es decir, de un hablar popular mexicano. En ese mismo sentido, es importante mencionar que la narrativa de Mendoza recrea, acaso como ninguna otra narrativa contemporánea, el hablar popular mexicano, y lo hace con una fluidez, riqueza y naturalidad excepcional. Por ello, los ejemplos de la narrativa
} 
ción de Lara. El solapamiento tiene lugar gracias a la constante incorporación histórica y pragmática ${ }^{5}$ que los hablantes hacen en el uso de la lengua. Ante tal afirmación surgen preguntas que si bien traspasan el límite de lo lingüístico y discursivo, apelan al contexto histórico en que el fenómeno idiomático sucede. Las preguntas podrían ser: ¿en qué momento, cómo y por qué ha sido posible que un hablar originalmente circunscrito a grupos sociales desfavorecidos se haya incorporado a un hablar más generalizado?

En su ensayo “'Ahí está el detalle’: el habla y el cine de México", producto de una conferencia presentada en el Congreso Internacional de la Lengua, celebrado en Zacatecas, en 1997, Carlos Monsiváis encuentra que "el habla popular urbana proporciona un prestigio inusitado al cine mexicano; de hecho, el primer prestigio evidente de su historia" (1997: 8). Monsiváis considera que el cine mexicano de los años cuarenta modificó el modo de hablar tanto en la ciudad de México como en el país. Se proclama, dice, la legitimidad del habla popular a través de Cantinflas, Tin-Tan, David Silva y Pedro Infante. Se trata de una conquista de lo marginal. El hablar laberíntico de Cantinflas, el hablar pachuco de Tin-Tan, los juegos lingüísticos de Pedro Infante ganan una

de Elmer Mendoza, expuestos en este artículo, aparecen como punto de partida y vértice de la tradición discursiva que nos ocupa: la esgrima conversacional. Para una discusión actualizada sobre el valor y la naturaleza de la oralidad en el texto literario, véase Córdova, 2016b.

5 Tal como Lara señala, el concepto de tradición discursiva popular y culta tiene su origen en la escuela de Eugenio Coseriu y han sido extendidos por Österreicher, Koch y Kabatek. Sin embargo, existe una contribución original en la propuesta del lingüista mexicano, pues él les otorga un “(...) sentido concreto en relación, tanto en la teoría de la acción verbal como con la historia de la lengua española” (2015: 32). 
legitimidad que dará lugar a que, más tarde, gran parte de la población mexicana utilice variantes del habla popular o se identifique con ellas, sin importar su adscripción social. Pero no sólo el cine, también la música que se difunde en la radio, servirá para instalar una tradición verbal que mimetiza, pero también recrea estas tradiciones verbales. La prosopopeya y el hablar impostado o engolado, ceden el lugar prestigioso a un hablar más espontáneo y creativo, pero sobre todo auténtico, acorde a las nuevas condiciones sociales del país. El empoderamiento de grupos originalmente proscritos al analfabetismo elemental o funcional, implicó la incorporación de lo originalmente vulgar a lo aceptable y aplaudido. De tal manera que la épica de los nuevos protagonistas del siglo xx no sólo se instaló en el muralismo o la narrativa de la Revolución Mexicana, también tomó forma en el cine y en las tradiciones verbales populares con las que se recrearon las nuevas realidades sociales. ${ }^{6}$

De ahí que se puede afirmar que existe un contexto cultural e histórico que propicia la circulación de nuevas variantes verbales cuyo origen puede explorarse sociolingüísticamente y cuya dinámica de uso responde a condiciones estilísticas y contextos situacionales. Para hacerlo es útil recordar las tres competencias con que Coseriu (1992) afirma que se puede explicar el hablar como hecho lingüístico: la competencia general, la competencia histórica y la competencia textual. Las tres competencias ordenan la posibilidad de un análisis integral y nos advierten de las limitaciones de un análisis fragmentario. Lara se refiere a tres aspectos del

\footnotetext{
${ }^{6}$ Documento este punto en la última parte del artículo.
} 
saber hablar que nos colocan en la segunda y tercera competencia de Coseriu: "el de lo que constituye la lengua histórica, el del papel de las tradiciones verbales y el del papel de la normatividad en el saber hablar" (2009: 12). Propuesta sumamente útil en este análisis, pues la lengua histórica no es lo mismo que la tradición verbal. Las tradiciones verbales implican contextos pragmáticos y son observadas en momentos precisos de una lengua. La tradición verbal atraviesa la historia porque es parte de las prácticas discursivas comunitarias que cambian y matizan su uso a lo largo del tiempo, de la historia. La tradición verbal es parte de la práctica discursiva y esta es parte del saber hablar que, a su vez, corresponde a una competencia pragmática y textual de la lengua que, como es sabido, alude al rol social de los participantes y a las particularidades del género y la situación en que sucede el acto comunicativo. Lara disecciona la competencia histórica de Coseriu, retira los reflectores de la competencia lingüística general y hace converger, tal como Coseriu esboza - pero no desarrolla-, lo histórico, lo pragmático y lo textual.

Un concepto en el que se entrelaza de manera singular lo histórico, lo pragmático y lo textual es el de tradición discursiva (TD), desarrollado en el marco de la lingüística románica alemana y claramente explicado por Kabatek (2014). La tradición discursiva reduplica la lengua en acción como sistema general y la forma textual como patrimonio histórico. Y aunque es la reduplicación textual lo que interesa a los estudiosos de las tradiciones discursivas — nos advierte Kabatek - es imprescindible considerar que tal iteración sólo es posible a través de un fenómeno que hace converger lo pragmático y lo histórico en un hecho lingüístico: la 
evocación. La TD es evocada por contextos cotidianos, por instituciones o por modos discursivos ${ }^{7}$ (correo electrónico, mensaje de texto, oralidad, etcétera). La evocación sucede entre un texto y una situación, o viceversa. A su vez, tal situación genera, a lo largo del tiempo, situaciones similares repetidas y textos similares repetidos generando la evocación. Si pretendiéramos sintetizar en una fórmula la producción de las tradiciones discursivas, quedaría así:

$$
\mathrm{TD}=\mathrm{T} 1 . . . \mathrm{Tn}+\mathrm{S} 1 \ldots \mathrm{Sn}(\mathrm{E})
$$

$$
\begin{aligned}
& \mathrm{TD}=\text { tradición discursiva } \\
& \mathrm{T}=\text { texto } \\
& \mathrm{S}=\text { situación } \\
& \mathrm{E}=\text { evocación }
\end{aligned}
$$

En gran medida es la consideración de la evocación lo que explica que la TD no sea lo mismo que un género textual o que un texto. La evocación apela a condiciones pragmáticas delimitadas por la historicidad que conlleva el uso de la lengua. Mientras que el análisis textual se deslinda de la historicidad de los mecanismos pragmáticos que dan cohesión y coherencia al texto. Lo mismo sucede con el géne-

\footnotetext{
${ }^{7}$ Se asume aquí el concepto de "modo discursivo" de Halliday (1982), para quien el registro discursivo se compone de: campo del discurso, modo del discurso y tono del discurso. El modo del discurso se contempla en un continuum en el que los extremos son lo oral y lo escrito. Hay textos que son escritos para que se lean como si se escucharan, tal es el caso de los chats sincrónicos. El correo electrónico sería muy escritural si reproduce el modelo de una carta institucional. El modo del discurso prototípico de la oralidad es aquel que tiene mayor espontaneidad, se somete a las condiciones del aquí y ahora.
} 
ro textual, cuando apelamos al género, aislamos la estructura que lo caracteriza, al margen de las condiciones de evocación. Situación que no sucede cuando se utiliza el concepto de tradición discursiva.

La tradición discursiva no es, entonces, un concepto ocioso. Todo lo contrario. Es necesario porque con él rescatamos ese vértice en que el hablar es historia y es acontecimiento pragmático. Lo mismo sucede con el concepto de tradición verbal (Lara, 2012 y 2015) que permite apreciar la distensión y contracción idiomática de usos léxicos singulares, anteriormente sólo acotados y fijados en la jerga o argot, pero ahora siguiendo la perspectiva de Lara-, explicados a la luz del acto verbal, del diálogo (2012: 55). Las tradiciones verbales atraviesan y traspasan las tradiciones discursivas; de alguna manera tienen mayor longevidad porque son microestructuras verbales que versátilmente aparecen en distintas manifestaciones lingüísticas. Porque perviven y exceden su espacio y tiempo original de uso es posible identificarlas. Por ello, tal como anota Lara, se explica que una jerga como la de los pachucos haya pasado a formar parte del habla popular mexicana. ${ }^{8}$

Lara reconoce la existencia de tradiciones verbales cultas y tradiciones verbales populares. La tradición verbal es un concepto con el que es posible apreciar el uso de la lengua en su expresión dinámica e histórica más allá de los tipos textuales y de una macro-contextualización pragmática. Se trata de un concepto-abanico que podemos ampliar o cerrar, según sea el radio en que estamos apreciando y analizando el fenómeno idiomático. De ahí que se pueda hablar de una tradición verbal

\footnotetext{
${ }^{8}$ Véase la nota 4.
} 
culta del español de México, del español hispanoamericano, o del español en general (Lara, 2015). Así también es posible y plausible documentar tradiciones verbales populares que delinean la identidad lingüística de una comunidad de hablantes, a través de esquemas creativos concretos (Lara, 2012).

Las tradiciones verbales populares o cultas son concebidas en el nivel idiomático de la lengua. Es decir, identificamos expresiones verbales y las contextualizamos históricamente, algunas veces utilizando rasgos socioculturales de quienes las utilizan. Por su parte, la tradición discursiva es identificada en una dimensión no sólo idiomática e histórica, sino textual y concretamente pragmática. Con la tradición discursiva, delimitamos las condiciones socioculturales que evocan su uso, la colocación enunciativa de quienes intervienen en ella y la naturaleza discursiva que se origina. De tal manera que las tradiciones verbales se pueden permeabilizar a través de distintas tradiciones discursivas.

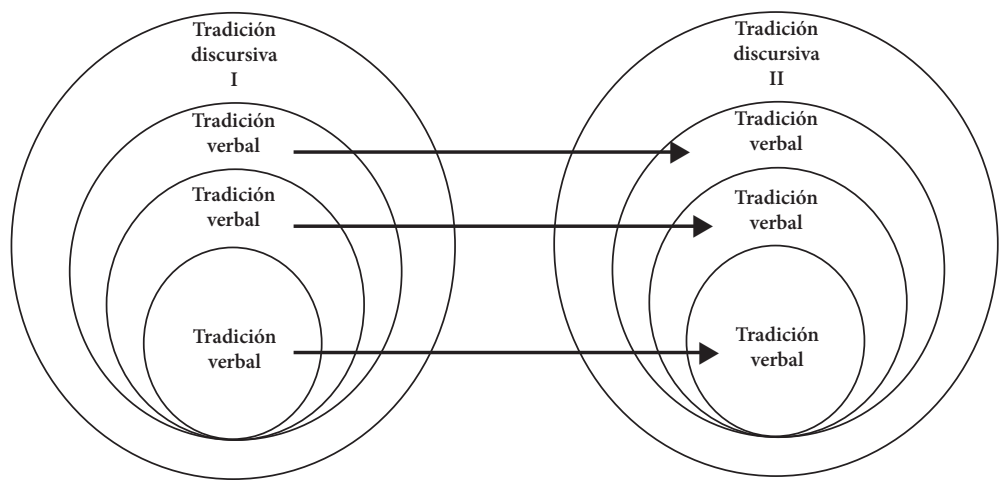

Figura 1. Tradición verbal y tradición discursiva 


\section{La esgrima conversacional}

Si bien es cierto que la espontaneidad, improvisación y expresividad son rasgos característicos del habla coloquial que se manifiesta, en diversos grados, en distintas comunidades lingüísticas, no podemos negar que existen particularidades que se acotan por la cultura de la comunidad y por el grado de familiaridad y carácter de los hablantes. Además, tales particularidades, una vez que aparecen de manera repetitiva en un contexto comunicativo, crean una evocación ${ }^{9}$ recurrente y generan una tradición discursiva que, a su vez, es susceptible de ser atravesada por tradiciones verbales específicas.

Analizaré aquí una tradición discursiva que puede ser observada en situaciones bien localizadas de oralidad espontánea, o en su recreación en los textos literarios o audiovisuales. De manera particular, analizo su presencia en uno de los textos narrativos de Élmer Mendoza, Balas de plata (2008), y refiero otras tradiciones discursivas con las que se relacionó en su origen. La esgrima conversacional ${ }^{10}$ es una

\footnotetext{
${ }^{9}$ Los ejemplos de evocación que anuncian la tradición discursiva son de carácter pragmático y cultural. Pensemos en el saludo. Encontrarse por la mañana con el vecino, evoca el saludo matutino y cotidiano. Entrar al consultorio médico evoca una interacción de preguntas y respuestas respecto a la condición del paciente que no se darían en otro espacio. Algunas revistas de entretenimiento evocan la existencia de un editorial que introduzca el número. Y ese editorial evoca una enumeración específica: motivaciones del contenido, justificación y explicación, por mencionar algunos. Existen condiciones de enunciación esenciales y accidentales. Las condiciones esenciales de enunciación son las que evocan una tradición discursiva.

${ }^{10}$ El término de esgrima conversacional lo presenté por primera vez en el Primer Congreso Internacional de Glotopolítica celebrado en agosto de 2015 en la Universidad de Chile. Más tarde lo retomé en el XIII Congreso Nacional de
} 
tradición discursiva no exclusiva, pero sí característica del hablar popular mexicano y es depositaria, a su vez, de una tradición verbal popular mexicana.

Explico ahora cuáles son las condiciones pragmáticas que evocan esta tradición discursiva y, posteriormente, desglosaré las regularidades discursivas que es preciso que se presenten para su identificación.

La esgrima conversacional sucede en contextos situacionales de habla coloquial muy informal, entre hablantes avezados, dicharacheros y espontáneos. Aún puede escucharse en el mercado, entre comerciantes, entre conversadores que comparten alta "confianza" y, a diferencia de otras tradiciones discursivas a las que les podría bastar un turno de habla para ser identificadas - como el piropo, el albur, o el choteo $^{11}$ en $\mathrm{Cub}$-, la esgrima conversacional tiene al menos un intercambio entre dos hablantes proactivos, es decir, al menos dos turnos de habla.

En la medida que la esgrima conversacional se nutre de la tradición verbal popular mexicana, es posible encontrar en sus manifestaciones variantes léxicas atribuidas al habla del hampa, al hablar de germanía, al espanglish, o a variedades regionales, las cuales formarían parte de tradiciones verbales mexicanas.

Lingüística Aplicada realizado en octubre del mismo año en la Universidad Autónoma de Chiapas. Finalmente, ese mismo año, en el VII Coloquio de Cultura Mexicana, en el marco de la Feria Internacional del Libro, presenté una ponencia titulada "La esgrima conversacional en Balas de plata de Élmer Mendoza", en la que recogía ya las conclusiones preliminares de este concepto analítico.

${ }^{11}$ Agradezco las observaciones sobre el choteo isleño que me proporcionaron mis alumnos José Raúl Gallego y Susadny González Rodríguez. 
La esgrima conversacional es una forma de expresión coloquial, lo que explica la importancia de la espontaneidad con que sucede y su imitación. A esta condición de la oralidad es posible agregar la proclividad cultural que Mañach (1955) encuentra en la cultura cubana, y en la criolla, en general. A su entender, la idiosincrasia cubana gozaría de una "rápida agilidad mental" para hacer jocoso lo serio, para chotear. El desafío de la autoridad; el deseo de ver caer, simbólicamente, al competidor de la vida; la adicción a la familiaridad; la tendencia a desvalorizar, a chotear; la resistencia a la jerarquía; la aversión a la ejemplaridad, todo ello mostraría para Mañach tendencias con que se instala un yo particular del cubano. $\mathrm{Y}$ algunas de estas características coincidirían con la idiosincrasia criolla americana. Tal estilo y carácter convergerían, además, con cierta tendencia andaluza al pitorreo. Y, desde mi perspectiva, esa tendencia a la espontaneidad, frescura, $y$ a la burla abierta se puede encontrar en lo popular de diversas culturas. ${ }^{12}$

Para que la esgrima conversacional suceda es necesario que existan las siguientes condiciones en el intercambio lingüístico:

\footnotetext{
${ }^{12}$ Vale la pena mencionar el valioso estudio de William B. Irvine (2015) ¿Por qué duelen los insultos?, en donde reflexiona sobre el papel de la burla y del insulto en la cultura humana en general. Irvine atribuye a una programación evolutiva de la especie humana la necesidad de triunfar a través de la burla o el insulto. Este triunfo simbólico respondería a esa programación que garantizaría la supervivencia. Su argumento viene a coincidir con el mío en el atribuir a todas las culturas humanas esta tendencia confrontativa. En todo caso, es la conciencia lingüística y el carácter del hablante lo que modularía la confrontación discursiva. Así las cosas, la esgrima conversacional, en tanto que confrontación verbal, estaría latente en todos los grupos humanos. Sin embargo, en este trabajo se hace una delimitación de ésta según su aparición en contextos culturales mexicanos.
} 
1. Sucede entre dos hablantes.

2. Las interacciones suceden con agilidad mental y verbal por parte de los dos hablantes.

3. Hay referencias directas a la primera y segunda persona.

4. La frases cortas se marcan por la propia extensión proposicional, por la prosodia o, en el caso de los textos escritos, por la puntación.

5. Sucede con lenguaje indirecto que puede darse a través de elisiones, metáforas, comparaciones o ironías.

6. La intención del discurso mostrada es el ingenio, donaire o afrenta.

7. Es realizada abrevando de la tradición verbal popular.

\section{La esgrima conversacional en la narrativa de Élmer Mendoza.}

Si uno lee con curiosidad idiomática la narrativa de Élmer Mendoza salta a la vista que el lenguaje con que se construye el habla de sus personajes no responde exclusivamente a un dialecto culichi, ${ }^{13}$ como se sugiere en diversos artículos de difusión sobre su obra (Campbell, 2014). Las variantes léxicas incluyen el caló mexicano, o habla del hampa, espanglish y expresiones que bien se pueden atribuir a una tradición verbal popular mexicana. Algunas de éstas, tal como ha encontrado Lara (1992), no se pueden considerar exclusivas

${ }^{13}$ El Diccionario del español de México registra culichi como coloquialismo para culiacanense. 
de una jerga, tal como se llegó a plantear, erróneamente, al hablar del pachuco. Luis Fernando Lara mostró que, en realidad, muchas de las variantes atribuidas al pachuco se encuentran en el hablar popular mexicano.

En Balas de plata he localizado al menos 15 interacciones en las que se realiza la esgrima dialógica. Sólo analizaré tres de estas interacciones. Pretendo mostrar cómo funcionan las siete características encontradas en esta tradición discursiva, la esgrima conversacional. En el primer caso que presento, el detective judicial, el Zurdo Mendieta, habla con un testigo que estaba involucrado sentimentalmente con la víctima. El testigo es un joven irreverente. La parte de la conversación en que sucede la esgrima conversacional la he reproducido en cursivas y para indicar los turnos de habla he introducido diagonales.

1. Situación: Mendieta aborda su automóvil. Se acerca el chico de la bici. ${ }^{14}$

Lléveme preso, poli, porque voy a matar al culpable./ Fue suicidio./ Pero fue por un tarado que la embaucó, ese güey no amanece, ya dije./ ¿Quién es?/ El abogado del diablo./ Ah, ya se te adelantaron, amaneció con un agujero en la frente./ No me diga./ No preguntes, ¿y tú que pitos tocas?/ Nomás, soy el chaca del club de enamorados de la reina y el hijo de mi madre./ Pues caminaron, morros, los dejaron abanicando la brisa.

(Balas de plata, p. 42)

\footnotetext{
${ }^{14}$ Las condiciones de simetría o familiaridad entre los hablantes que hacen esgrima conversacional pueden darse por el género, la clase o rol social, empatía, entre otros. En este caso, se trata de un adolescente y un hombre adulto que comparten el mundo de la calle y el género.
} 
Como puede observarse, la esgrima conversacional está compuesta de cuatro turnos de habla. Como se ha mencionado, la esgrima conversacional es una tradición discursiva en la que se mencionan las personas de la enunciación: primera y segunda persona. En este caso, entran con una interacción rápida de dos frases cortas: "No me diga/No preguntes", interacción que ha sido documentada en la película Escuela de vagabundos (1954) en la que actúa Pedro Infante. ${ }^{15} \mathrm{El}$ juego verbal consiste en que la metáfora "No me diga", que corresponde a un "qué increíble", es tomada literalmente por el interlocutor, ${ }^{16}$ es decir desmetaforizada, para construir una ironía, que es un insulto velado, en el momento en que responde "No preguntes". De manera inmediata el detective utiliza otra metáfora: “¿y tú qué pitos tocas?", que equivale a "por qué te involucras" o "por qué te metes en esto", y que corresponde también, en la tipología de tradiciones verbales populares de Luis Fernando Lara (2012), al primer tipo porque se parte de la pregunta base “¿qué pasó?" para llegar al “iqué pitos tocas?”. Ágilmente el destinatario responde con dos largos atributos, el primero es una hipérbole, y el segundo un pleonasmo, con los que intenta eclipsar la pregunta insultante del detective: "Nomás, soy el chaca del club de enamorados de la reina y

\footnotetext{
${ }^{15}$ Agradezco la observación a mi alumna Corina Ramírez. La interacción no sólo está en la película Escuela de vagabundos (1954) con Pedro Infante, sino que es recurrente en Cantinflas. Este ejemplo, y otros, muestran cómo la tradición verbal mexicana se recrea no sólo en el cine clásico mexicano, sino en las coplas del siglo xx. Abordo este punto en el último apartado del artículo.

${ }^{16}$ Monsiváis señala cómo Cantinflas "toma los insultos al pie de la letra para desbaratar su impulso" (1988: 93). En este caso, el recurso es el mismo aunque no se trate de un insulto.
} 
el hijo de mi madre". Tanto la variante apocopada "nomás" como la variante "chaca", cabeza de gallina en Chiapas, según Santamaría, son parte del habla popular. Ante ello, el interlocutor revira con dos metáforas que aluden a la inutilidad del hablante y de sus amigos: "caminaron morros" y "los dejaron abanicando la brisa". La variedad no cesa: se introduce la variante culichi morros por "niños" o "chavos", y se acompaña de otra creación también del esquema número uno de Lara, en el que la sustitución es de varios vocablos de una metáfora más usual: "los dejaron abriendo la boca" aparece aquí como "los dejaron abanicando la brisa", lo cual significa "los dejaron sin obtener lo que esperaban". A la agilidad interactiva, con la que parecen disputarse el trofeo al que mejor esgrime verbalmente, se suman las variantes del hablar vernáculo.

En el siguiente ejemplo, el intercambio sucede vía telefónica entre dos judiciales. Se abre el torneo in medias res, sin mayor preludio que un saludo propio del habla coloquial mexicana y un vocativo que alude a la preferencia sexual del destinatario: "Qué onda, maricón". De manera inmediata se alude a la autoridad anónima del rumor: "ya me enteré". Acto seguido, en el mismo turno de habla, el investigador, compañero de Mendieta, le recomienda disimular la supuesta orientación sexual del contrincante, y cierra el turno advirtiendo sobre un posible rumor con el que se pondría en duda la orientación sexual de la corporación: "van a creer que se le hace agua la canoa". La metáfora, como esquema de la tradición verbal popular, aparece como recurso lúdico y como touché con el que el interlocutor, sin duda, reaccionará. 
2. Ortega a Mendieta. Teléfono.

Ortega en línea: Qué onda, maricón, ya me enteré, deberías disimular, al rato van a creer que a toda la corporación se le hace agua la canoa./ Y qué, si lo sabe Dios que lo sepa el mundo. /Pues aquí ya surgieron tus valedores, eso explica por qué desde hace rato no se te conoce a nadie./ La verdad fue una decisión difícil, por lo mismo pienso iniciar hasta el verano, y como estás en mi lista prometo que serás el primero./ Ni loco, son siete años de sal, oye, ¿viste lo que me pediste sobre el sedán de Canizales?, definitivamente lo movieron la noche del crimen (...).

(Balas de plata, p. 138)

El intercambio de esgrima se compone, en este caso, de cinco turnos de habla. Los ritmos prosódicos se marcan con la puntuación y con la extensión del turno. El recurso es ideal para recrear la sintaxis segmentada que caracteriza al habla coloquial, ${ }^{17}$ aunque sin las discordancias o elisiones que caracterizan al habla espontánea real. Con ello, el escritor suma verosimilitud a un registro oral con el que constantemente entran en escena sus personajes. En el primer ataque se observan dos ironías: "ya me enteré" y "deberías disimular". Se trata del punto de partida de la esgrima, un Attaque au fer. ${ }^{18}$

\footnotetext{
${ }^{17}$ La sintaxis cercenada o parcelada que caracteriza a la expresión coloquial ha sido analizada y documentada por diversos autores. Las frases cortas, la inserción de elementos lingüísticos que no concluyen en una oración de forma canónica, las elisiones, los elementos de relleno, las condiciones de inmediatez, la prevalencia de la expresividad sobre la información compartida, el uso de códigos paralingüísticos, permiten esta condición. Véanse, entre otros, Vigara Tauste, 1992; Narbona, 1991 y1992; Cortés, 1986.

${ }^{18}$ Ataque al hierro. Hay batimiento, presión y frotamiento.
} 
El lector sabe que son ironías porque la narración registra que el Zurdo Mendieta no es homosexual y que está enamorado de Goga, una mujer casada con quien tiene una relación sexual y sentimental. Pero Goga, una mujer osada, ha mandado un ramo de flores al detective y lo ha hecho a la oficina. El Zurdo hace un salto hacia delante, una balestra: su respuesta es una ironía fosilizada e hiperbólica: "si lo sabe Dios que lo sepa el mundo", que es un refrán compartido en la tradición verbal mexicana. De esta manera, el Zurdo pretende desactivar la agresión ritual de Ortega. Pero éste no se da por enterado y advierte sobre los "valedores", los amigos, y sobre la razón por la que Mendieta no ha tenido pareja: "eso explica por qué desde hace rato no se te conoce a nadie". Ante este nuevo Changez-Froisse, ${ }^{19}$ Mendieta contesta con otra ironía con la que trata de comprometer ahora la virilidad de Ortega: fue una decisión difícil ....y "como estás en mi lista prometo que serás el primero". Se trata de presionar al contrincante, un Changez-Pressez, ${ }^{20}$ que funciona básicamente a través de la elisión "serás el primero". El duelo termina con un Bond en arrière, es decir, un salto atrás que lo hace poner de nuevo los pies en la tierra, un rechazo supersticioso de Ortega a la impostada propuesta homosexual: "ni loco, son siete años de sal". El sentido ritual de la esgrima se percibe con el abrupto cambio de tema que se introduce con el marcador conversacional que constituye el imperativo "oye" y la

\footnotetext{
${ }^{19}$ Changez-Froisse, cambio con frotamiento. Es un cambio de enganche que termina por un frotamiento sobre la hoja del adversario desde la punta a la parte fuerte. Se hace con presión violenta.

${ }^{20}$ Changez-Presse, cambio con presión sobre la hoja del contrincante.
} 
introducción de un nuevo tema, el trabajo: Ortega informa sobre las pesquisas que ha hecho sobre el crimen.

"Se te hace agua la canoa", que significa que el hombre no tiene una orientación heterosexual, y "si lo sabe Dios que lo sepa el mundo", que se refiere a la decisión de transparentar una situación, son frases que podemos incluir en la tradición verbal popular mexicana. El primer caso puede incluirse en las metáforas características de tal tradición. Mientras que en el segundo tenemos un refrán.

Como puede observarse, aquí la esgrima conversacional es una especie de mascarada en la que uno de los hablantes se traviste idiomáticamente, asume un género que no le corresponde, y a través de metáforas, ironías, y haciendo uso de la tradición verbal popular se enfrenta a la investidura que le atribuye su interlocutor. Aceptar la burla es una manera de garantizar al burlador que su interlocutor no es una amenaza (Irvine, 2015). De ahí que sea posible que la afrenta se convierta en un ritual de pertenencia varonil (Labov, 1972).

Mientras que el insulto no es una parte prioritaria en la esgrima conversacional, la confianza entre los participantes sí lo es. Es necesario que exista una relación de cercanía entre el emisor y el destinatario que esté dada por el género, la clase social, la simpatía, la amistad o la jerarquía compartida. En la narrativa que analizamos sobresale su uso entre personajes del género masculino, caracterizados como parte de la clase media o media baja. Aunque también encontramos un caso entre el Zurdo Mendieta y su asistente Gris, una mujer que anteriormente era agente de tránsito. En la novela, tanto la empatía entre el chico de la bici y el detective Mendieta, como entre éste y su colega Ortega, marcan los pasajes 
más significativos de esgrima conversacional, tanto en extensión como en riqueza en el uso de recursos idiomáticos. La siguiente esgrima sucede también vía telefónica, entre el detective judicial Mendieta y el chico de la bici, un testigo presencial. La llamada es iniciada por un testigo mucho más joven que el policía, pero con una clara relación de confianza e incluso irreverencia hacia el policía.

\section{Chico de la bici a Mendieta.}

Mi poli, ¿es usted?/ ¿Quién más?/ Christina Aguilera, por ejemplo, que está a punto de tener un hijo mío./ Ah/ ¿Está borracho?/ Cómo crees, qué pasó./ Hoy amanecí con un ataque de decencia, empeoré durante el día y en este momento no resisto más, quiero hacer un servicio a la sociedad./ No me digas./ No pregunte./¿Llamaste a la Sociedad Protectora de Animales?/ Quise contarles pero me mandaron con usted, con el Zurdo Mendieta, el placa más prendido de la ciudad.I ¿Quieres confesar?/ ¿Sabe que mi padre me sacaría en siete minutos por cualquiera de las dos causas?/ ¿Quién es?/ La vieja Inés, investigue, mi poli, ¿por algo anda en el ajo, no?, ¿su morra también murió?/ Casi./ Esto es vivir en el infierno, mi poli, a poco no, en mi perra vida me había sentido tan gacho, por eso quiero que haga su arresto y lo declaren el poli del mes y le den un cheque para que no le falte el perico y la cerveza y pueda sobrellevar su pena./ Tú dirás./ No se lo voy a decir por teléfono, puede que haya pájaros en el alambre, sólo le adelantaré que el día que se hizo la machaca vi salir a la reina de su casa, serían las tres y media de la madrugada, me trepé a mi baika y ahí te voy, imaginaba adónde se dirigía, le hice plantón en la casa del enemigo pero nunca llegó, lo que vi le va a costar una lana ¿le parece la mitad del cheque que va a recibir?/ Es justo./ Usted dice dónde nos 
vemos, ah y que sea mañana, porque ahora estoy leyendo,¿sabe qué me dejó de herencia, mi morra?, un libro/ ¿Y crees que te quería esa mujer?; alguien que te pone a leer te odia desde lo más profundo de su ser./ Calle boca, mi poli, calle boca./¿Viste entrar o salir al asesino?/ Qué pasó, mi poli, no sea gandalla, mañana le voy a soltar la sopa, pero por la tarde porque en el día voy a estar ocupado ejerciendo mi decencia./ No me digas./ No pregunte, como dice usted./ ¿Por qué no ahora?/ Porque es tiempo de otra cosa, más dulce y agradable. A las seis en el Miró./ Que sea a las siete y en Las Ventanas, para que se mueran los feos.

El joven desea colaborar con información sobre el asesinato de la chica de la que estaba enamorado y el detective necesita la información. La prolijidad del joven puede, a primera vista, hacer percibir que éste es más creativo, mientras que las interacciones cortas del policía son en principio irónicas. Es un pasaje sumamente creativo en el que, sin embargo, el lector tiene la impresión de estar escuchando un diálogo espontáneo de notable fluidez. El escritor lo logra utilizando las frases cortas que imitan la sintaxis parcelada de la oralidad, insertando elementos léxicos de la tradición popular mexicana y, finalmente, dando forma a esa característica forma dialógica que representa la esgrima conversacional. Cuando el joven pregunta "Mi poli, ¿es usted?", Mendieta contesta "Quién más". Cuando el joven dice irónicamente que "quiere hacer un servicio a la sociedad", el detective contesta con otra ironía: "No me digas". A ésta le sigue otra " ¿llamaste a la Sociedad Protectora de Anima- 
les?", ante la cual el chico da un Changez-Coulez, ${ }^{21}$ un cambio con filo: "Quise contarles pero me mandaron con usted, con el Zurdo Mendieta, el placa más prendido de la ciudad", de donde el lector infiere que es precisamente el detective el más adecuado para tratar con "animales". Estamos frente a una Contra-Respuesta, Contre-Riposte, del hablante que reacciona a un Attaque au fer, ataque de hierro, que comprende una respuesta de corta duración sobre el metal contrario. Con ésta el hablante responde brevemente a otro ataque corto: "No me digas. No pregunte". Más adelante, el Zurdo Mendieta suelta tres ironías más: “¿Quieres confesar?”, “¿Y crees que te quería esa mujer?; alguien que te pone a leer te odia desde lo más profundo de su ser", y nuevamente, "No me digas", que aunque representa un cliché cuenta aún con fuerza irónica. Por su parte, las intervenciones del joven son más creativas, ágiles y extensas, tal como se puede apreciar en el siguiente cuadro.

\begin{tabular}{|l|l|}
\hline El chico de la bici & El Zurdo Mendieta \\
\hline Mi poli, ¿es usted? & ¿Quién más? \\
\hline $\begin{array}{l}\text { Christina Aguilera, por ejemplo, que } \\
\text { está a punto de tener un hijo mío. }\end{array}$ & Ah \\
\hline ¿Está borracho? & Cómo crees, qué pasó \\
\hline $\begin{array}{l}\text { Hoy amanecí con un ataque de } \\
\text { decencia, empeoré durante el día y en }\end{array}$ & \\
\hline
\end{tabular}

${ }^{21}$ Changez-Coulez. Así se nombra en esgrima el cambio con filo que se da aprovechando que la posición en guardia del contrincante está mal cerrada. El atacante tiene la espada en posición externa, hacia arriba. 


\begin{tabular}{|c|c|}
\hline $\begin{array}{l}\text { este momento no resisto más, quiero } \\
\text { hacer un servicio a la sociedad. }\end{array}$ & No me digas \\
\hline No pregunte. & $\begin{array}{l}\text { ¿Llamaste a la Sociedad Protectora } \\
\text { de Animales? }\end{array}$ \\
\hline $\begin{array}{l}\text { Quise contarles pero me mandaron } \\
\text { con usted, con el Zurdo Mendieta, el } \\
\text { placa más prendido de la ciudad. }\end{array}$ & ¿Quieres confesar? \\
\hline $\begin{array}{l}\text { ¿Sabe que mi padre me sacaría en } \\
\text { siete minutos por cualquiera de las } \\
\text { dos causas? }\end{array}$ & ¿Quién es? \\
\hline $\begin{array}{l}\text { La vieja Inés, investigue, mi poli, ¿por } \\
\text { algo anda en el ajo, no?, ¿su morra } \\
\text { también murió? }\end{array}$ & Casi \\
\hline $\begin{array}{l}\text { Esto es vivir en el infierno, mi poli, a } \\
\text { poco no, en mi perra vida me había } \\
\text { sentido tan gacho, por eso quiero que } \\
\text { haga su arresto y lo declaren el poli del } \\
\text { mes y le den un cheque para que no } \\
\text { le falte el perico y la cerveza y pueda } \\
\text { sobrellevar su pena. }\end{array}$ & Tú dirás \\
\hline $\begin{array}{l}\text { No se lo voy a decir por teléfono, puede } \\
\text { que haya pájaros en el alambre, sólo } \\
\text { le adelantaré que el día que se hizo la } \\
\text { machaca vi salir a la reina de su casa, } \\
\text { serían las tres y media de la } \\
\text { madrugada, me trepé a mi baika y ahí } \\
\text { te voy, imaginaba adónde se dirigía, }\end{array}$ & \\
\hline
\end{tabular}




\begin{tabular}{|c|c|}
\hline $\begin{array}{l}\text { le hice plantón en la casa del enemigo } \\
\text { pero nunca llegó, lo que vi le va a } \\
\text { costar una lana ¿le parece la mitad del } \\
\text { cheque que va a recibir? }\end{array}$ & Es justo \\
\hline $\begin{array}{l}\text { Usted dice dónde nos vemos, ah } \\
\text { y que sea mañana, porque ahora } \\
\text { estoy leyendo, ¿sabe que me dejó de } \\
\text { herencia, mi morra?, un libro. }\end{array}$ & $\begin{array}{l}\text { ¿Y crees que te quería esa mujer?; } \\
\text { alguien que te pone a leer te odia } \\
\text { desde lo más profundo de su ser. }\end{array}$ \\
\hline Calle boca, mi poli, calle boca & ¿Viste entrar o salir al asesino? \\
\hline $\begin{array}{l}\text { Qué pasó, mi poli, no sea gandalla, } \\
\text { mañana le voy a soltar la sopa, pero } \\
\text { por la tarde porque en el día voy a } \\
\text { estar ocupado ejerciendo mi decencia. }\end{array}$ & No me digas \\
\hline No pregunte, como dice usted. & ¿Por qué no ahora? \\
\hline $\begin{array}{l}\text { Porque es tiempo de otra cosa, más } \\
\text { dulce y agradable. A las seis en el Miró. }\end{array}$ & $\begin{array}{l}\text { Que sea a las siete y en Las Ventanas, } \\
\text { para que se mueran los feos. }\end{array}$ \\
\hline
\end{tabular}

La desproporción en la extensión de las intervenciones responde textual y discursivamente a distintos supuestos. Es el joven quien tiene la información que quiere compartir con el judicial por lo que el texto de naturaleza dialógica se carga hacia este hablante, en extensión. Mientras que, discursivamente, el joven está caracterizado como transgresor, poderoso, pero también como alguien que sufre porque han matado a la joven de la que estaba enamorado. Esto último explicaría la marcada creatividad de sus turnos de habla. Sin embargo, la interacción adquiere simetría en el ritmo sostenido de los ataques y contraataques. El esgrimir mutuo 
los coloca en una relación de solidaridad de golpe y contragolpe.

\section{El origen de la esgrima conversacional entre tradiciones populares}

En este trabajo he tratado de acotar el concepto de esgrima conversacional como un concepto analítico cuya utilidad es identificar una tradición discursiva que, a su vez, se nutre de una tradición verbal mexicana del siglo xx que aún persiste. Pero si queremos indagar sobre el origen de esta forma discursiva, es necesario revisar el solapamiento que existe entre la esgrima conversacional y otras tradiciones discursivas populares como las coplas, el albur o los refranes. ${ }^{22}$ Como punto de partida, podemos establecer que cuando sucede la esgrima conversacional es posible que los hablantes echen mano de albures, refranes, que utilicen los esquemas de producción de la tradición verbal popular que ha identificado Lara (2012), o que se encuentren similitudes con los intercambios en tono de afrenta, que aparecen en la lírica popular mexicana, particularmente, en las llamadas coplas. Sin embargo, lo que distingue a la esgrima conversacional con respecto a los refranes y albures, que pueden aparecer como componentes, es la necesaria interacción ágil, proactiva y balanceada que se da entre los participantes. ${ }^{23}$

\footnotetext{
${ }^{22}$ Evidentemente, existen múltiples estudios sobre la copla (Frenk, 1975, 1977), el albur (Rivera Jordan, 2010) y el refrán (Pérez Martínez, 1996). Sin embargo, estos fenómenos no han sido analizados como tradiciones discursivas.

${ }^{23} \mathrm{Si}$ el lector desea profundizar en ejemplos en los que aparece la tradición ver-
} 
En el voluminoso Cancionero folklórico de México, ${ }^{24}$ recopilado y ordenado por Margit Frenk, es posible percatarse de la existencia de una red comunicante a través de la cual se extiende y legitima la tradición verbal popular del México del siglo xx consolidada, a su vez, en el habla popular que el cine mexicano clásico recreó y consagró. Uno de los criterios de selección de las coplas populares, entre los que no se incluyen los corridos, pero sí algunas de sus estrofas, es su aspecto tradicional. Se entiende lo tradicional popular como aquello que no es exquisito, que cuenta con una estructura intercambiable y un estilo que "la gente está acostumbrada a manejar activamente" (Frenk, 1975: xxvi). Las coplas son estrofas que habitan en una canción u otra, de una región a otra del territorio nacional, con variedades secundarias, que no atentan contra la independencia de la estrofa. Su estructura puede ser la cuarteta octosílaba, la sextilla, la seguidilla o la redondilla, y esta estructura es su propia unidad que se integra a la unidad melódica de una canción. Esta versatilidad hace que las coplas sean intercambiables entre canción y canción. Este hecho hizo posible su fluidez y tránsito a través de una amplia comunidad de hablantes que habitan de un extremo a otro del país.

En la medida que la copla recoge situaciones cotidianas del pueblo, en esa medida recrea diálogos posibles. El dialogismo es uno de los recursos retóricos que se encuentran

bal mexicana, la interacción dialógica, el insulto y la interrogación como muestras de oralidad en la narrativa de Élmer Mendoza, sugiero echar un vistazo a dos artículos míos publicados en 2016. Ver bibliografía.

${ }^{24}$ El Cancionero se compone de cinco tomos coordinados por Margit Frenk. Su publicación sucedió entre 1975 y 1985 . Ver bibliografía. 
en las coplas. Se imitan interacciones entre dos que se reclaman, se celebran, se coquetean, se burlan. De hecho, tanto en las coplas de amor, como en las de intención humorística, Frenk construye un cuadro sinóptico en el que da un espacio a las estrofas en las que aparece el discurso directo. En la siguiente copla "Gallo-gallina" se puede observar el dialogismo y la afrenta como intención pragmática. El hombre le reclama a la mujer porque está celoso. Y ella no duda en compararlo con un perro, con lo cual se logra una ida y vuelta en el diálogo.

-Oye bien lo que te digo, no se te vaya a olvidar:

cada vez que quiera verte ya no más te he de chiflar, al fin ya te acostumbraron en el rancho a pajarear. -Pareces perro de casa, que no deja de ladrar; si te sientes ofendido, no vengas a reclamar; ¡qué poca vergüenza tienes! Tú no me debes de hablar.

Poner en acción al individuo es una estrategia que otorga verosimilitud y realismo a la copla. Es más probable que los oyentes se identifiquen o experimenten un papel activo frente a una conversación que frente a una descripción. Esta interacción recreada acerca al género con la esgrima con- 
versacional. Sin embargo, este último logra mayor realismo porque su musicalidad es la de la lengua misma, sin música específica. Además de que en la esgrima la interacción es más compleja, según pudo observarse, por la forma y cantidad de turnos de habla. El ritmo del turno de habla no está sometido al ritmo de una canción popular.

Entre las coplas ofensivas para viejas, que compila Frenk y su equipo, se encuentra "La potranquita", recogida en 1956 y 1957, en Oaxaca, y en Apatzingán, Michoacán. En este caso el dialogismo se manifiesta con discurso directo en una sola vuelta: el hombre reporta, pero no hay respuesta de la mujer. El lenguaje es llano y la mujer se compara a sí misma con una fruta que puede ser magullada. La intención pragmática de quien la dice es denunciar la renuencia de una mujer, pero lo hace como cotilleo, no como interacción actualizada:

$$
\begin{aligned}
& \text { Me dijo una vieja fea: } \\
& \text { ¡No se acerque, no me arrugue!, } \\
& \text { ¡retire, por Dios, la mano!, } \\
& \text { si no compra, no mallugue”. }
\end{aligned}
$$

$\mathrm{Al}$ igual que en la esgrima conversacional, los refranes aparecen, en las coplas, como formas sucintas de aludir a la sabiduría popular. También son recurrentes los disfemismos, las referencias escatológicas y las referencias a humores. Tanto la copla popular como la esgrima conversacional son textos expresivos que no consideran necesario el pudor o la exquisitez. Sin embargo, la copla que se encuen- 
tra en la memoria lírica de cantantes silvestres o profesionales, no hace necesario sino su memorización, mientras que la esgrima conversacional no responde a una plantilla o estructura hecha. En la esgrima es necesario el ingenio y la rapidez para atacar y contraatacar. Además, en la copla, la interacción es dialogismo de una o dos vueltas. En la esgrima conversacional, aunque bien podemos estar ante una interacción recreada, en el texto literario o en el texto cinematográfico, la interacción es construida como acontecimiento verbal cotidiano.

El albur también aparece en la canción popular y en la esgrima conversacional. El albur es un doble lenguaje con el que se hace alusión indirecta a la sexualidad del interlocutor. La metáfora, el calambur, la rima, son recursos retóricos que se utilizan para realizarlo. Seguramente su origen está en el contexto de los léperos del siglo xıx de los que Guillermo Prieto escribe, en Memorias de mis tiempos. Los léperos eran mestizos afectos a los placeres ruidosos y a atizar el júbilo. Y la naturaleza del lépero se manifestaba, mejor que en ningún otro lado - afirma Prieto-, en la "canción callejera". Vale decir que para Prieto el lépero se corresponde con el manolo de la península. Se trata de pícaros decimonónicos, individuos que nacen en los márgenes de la sociedad y tratan de insertarse a través de la estafa. En la siguiente estrofa, que registra Guillermo Prieto, se pueden apreciar las variantes fonéticas del hablar popular, las metáforas sin exquisitez. Los tres primeros versos bien se pueden concebir como un refrán con el que se podría, simultáneamente, construir un albur: 
Soy de calidá de gallo

Que en llegando a lo macizo,

Me vuelvo santo postizo...

Después, que la parta un rayo

Por los favores que me hizo.

(Mijares, 1985: 72)

El lépero, y los cantantes que los representaban, alborotaba los barrios y las casas de vecindad. Para Guillermo Prieto, en estas canciones se perfila una intención íntima y afectos característicos de un pueblo que son transmitidos con la palabra de doble sentido y con la alusión a la costumbre. Estamos, pues, frente a lo que permanece porque se hereda de generación en generación: la disposición al vacilón verbal con el que se sintetiza una filosofía cotidiana.

Un personaje esencial en esta continuación de las tradiciones verbales populares decimonónicas es el payaso, tipo que dará origen al cómico de carpa de la primera mitad del siglo xx y que será otro pivote en el engranaje de la tradición discursiva que nos ocupa. El payaso recita versos satíricos y canta algunas estrofas. Antonio García Cubas, en El libro de mis recuerdos (1904), registra los siguientes:

El diablo la mujer es,

de quien el hombre va en pos, pues cuando no engaña a dos, es porque entretiene a tres.

-No te amo por interés te dirá "que a ti te quiero: tú eres mi delicia", pero 
no te fíes de la suerte

porque (cantando y bailando) la mujer más fuerte

al final se rinde al dinero.

(Mijares, 1985: 480)

En la rima recitada o en la copla, el pueblo despliega valoraciones compartidas sobre los problemas con que se enfrenta en la vida cotidiana. Aunque en las coplas, en algunos casos, es posible rastrear versos procedentes de textos cultos, estas tradiciones discursivas se caracterizan por contener una filosofía silvestre y ágil cuya solución no es sobriamente conceptual, sino jocosa o expresiva del enojo, desprecio o pretendida indiferencia ante la situación.

Ya en el siglo xx, podemos afirmar que el contexto histórico y cultural permitió que el hablar popular mexicano se fijara. En lo histórico, la Revolución Mexicana abrió un espacio protagónico al mestizaje idiomático que se reflejó en las instituciones públicas y en la épica revolucionaria que se desplegó en la literatura y en las artes. El Estado representó un papel determinante, pues puso a circular un nuevo grupo social con un estilo propio. De alguna manera, lo mestizo desplazó a lo criollo. En lo cultural, si por un lado la copla vivía en todo lo ancho del territorio, por otro, primero la carpa y luego el llamado Cine de Oro mexicano fueron el continente en el que se fijó y dio esplendor a las tradiciones verbales populares y a tradiciones discursivas propias de un hablar mexicano que reclamaba su derechoala originalidad ya una identidad propia.

Para Carlos Monsiváis, el arrabal se manifiesta en el melodrama y en el sentido del humor de la carpa. Más tarde, el cine industrializa ese modo de ser genuino (Monsiváis, 1988: 
83). La esencia de esa manifestación es verbal. En la carpa surge el éxtasis que provoca, al pueblo, el hablar sin sentido (Cantinflas) y mediante albures. Este hablar sin sentido, el calambur, el albur o el lenguaje indirecto cuenta con constantes alusiones sexuales que deberán ser muchas veces lo suficientemente veladas para que no sean censuradas. Monsiváis registra el testimonio del cómico Resortes, quien había sostenido este duelo de albures en una carpa: "Uno de mis patiños me dijo: 'Tu boca de colegiala, dibujada para mí, y le respondí: 'Mira como traigo el pirulî"' (1988: 83). Posteriormente, el inspector del gobierno lo habría visitado en el camerino recordándole que no debía "mandarse" en sus expresiones.

Contrariamente a lo que se podría decir, el albur no es siempre dialógico. Es emitido y el interlocutor puede o no captar el doble sentido; puede, o no, ignorarlo. Cuando la jerarquía de los hablantes es la misma es muy probable que el albur sea respondido en aras de ser más brillante, de no dejarse someter por la insinuación de quien ha dicho el primer albur. Si la jerarquía entre los hablantes no es simétrica es muy probable que el albur deba resolverse con el silencio, o con el triunfo de quien tiene mayor jerarquía. La vitalidad del albur en el habla popular mexicana es, en nuestros días, plena. Al margen de la condición socio-económica, o el perfil instructivo y cultural, se utiliza. Aunque existen contextos y hablantes que lo favorecen. El mercado, la camaradería, la masculinidad, la juventud, parecen constituir variables que hacen más propicio ese hablar dicharachero. ${ }^{25}$

\footnotetext{
${ }^{25}$ Algunos albures de reciente uso, recogidos entre mis alumnos, son: "Ten trapito para limpiar", "Me dijeron que te dicen el chico medallas", "Me dijeron que te desayunaste unos huevos al mentón", "Qué chidos tenis, me gustan para traer-
} 
A la copla festiva, las rimas de payasos, y el albur de carpa se suma la peculiar habla del "cuánto inflas", de Cantinflas. Ahí confluyen de manera acentuada todos los recursos característicos del habla espontánea: elisiones, iteraciones, suspensiones sintácticas (anacolutos), rellenos; y del discurso humorístico: equívocos, metáforas, ironías, dobles sentidos, calambures. Para Monsiváis, Cantinflas “(...) transparenta la vocación de absurdo del paria, en parte desdén y fastidio ante una lógica que lo condena y lo rechaza y encuentra materia prima en el disparadero de palabras, donde los complementos se extravían antes de llegar al verbo" (1988: 87) y su papel fue no sólo consolidar un medio de esparcimiento, sino la de convertirse en difusor de una identidad coloquial hispana hiperbolizada que trascendió su región y su clase social.

\section{Conclusiones}

La esgrima conversacional es una tradición discursiva mexicana cuyos orígenes pueden rastrearse, según hemos visto, en la canción callejera del siglo xix y en las coplas folklóricas del xx. Su característica esencial es la interactividad y la afrenta, pero no se reduce a éstas. Se trata de un combate elaborado entre el yo y el tú en el que también se pone a prueba la agilidad verbal del los hablantes. El punto de partida es un toque con el que se acusa, se reclama, se juzga y se espera la reacción. Aún en nuestros días, en las conversacio-

los de aretes", entre otros. El albur es una tradición discursiva que permanece en el habla popular mexicana y que ha superado las fronteras del arrabal. 
nes jocosas de algunas familias, existe el gusto por esta tradición. Se trata de probar la destreza dicharachera y mostrar un triunfo simbólico que, sin embargo, fortalece vitalmente al hablante que vence o que lo hace bien. La esgrima conversacional es una tradición discursiva en México porque existe un contexto que evoca la práctica y un conjunto de reglas pragmáticas no escritas que los participantes deben sostener. Si se es retado, se contesta con estrategias de lenguaje indirecto: metáforas, ironías, elisiones; todas ellas salpicadas de tradiciones verbales populares. Si no se contesta, es posible que quien inicia insista. La esgrima conversacional es una práctica cultural con la que los hablantes se vencen o encumbran. Si la canción popular mexicana estimuló y conservó la esgrima conversacional, el Cine de Oro mexicano contribuyó a fijarla y difundirla.

\section{Bibliografía}

Arjona Iglesias, M. (2004), "El habla popular: una idea visionaria del doctor Lope", en Disquisiciones sobre Filología Hispánica. In memoriam Juan M. Lope Blanch, México, Universidad Nacional Autónoma de México, pp. 33-38.

Campbell, F. (2014), La era de la criminalidad, México, Fondo de Cultura Económica.

Córdova, P. (2016a), "De la hipocorrección a la violencia verbal en la narrativa del narcotráfico", Tonos Digital, 30, pp. 1-25. 
Córdova, P. (2016b), "Nuevas notas acerca de una antigua relación: oralidad y literatura. El caso de la interrogación", Oralia, 19, pp. 325-344.

Contés, L. (1986), Sintaxis del coloquio. Aproximación sociolingüística, Salamanca, Universidad de Salamanca.

Coseriu, E. (1992), Competencia lingüística. Elementos de la teoría del hablar, Madrid, Gredos.

Frenk, M. (1975), Cancionero folklórico de México. Coplas del amor feliz, tomo I, México, El Colegio de México.

Frenk, M. (1977), Cancionero folklórico de México. Coplas del amor desdichado, tomo II, México, El Colegio de México.

Frenk, M. (1980), Cancionero folklórico de México. Coplas que no son de amor, tomo III, México, El Colegio de México.

Frenk, M. (1982), Cancionero folklórico de México. Coplas varias y varias canciones, tomo IV, México, El Colegio de México.

Halliday, M. (1982), El lenguaje como semiótica social. La interpretación social del lenguaje y del significado, México, Fondo de Cultura Económica.

Irvine, W. (2015), ¿Por qué duelen los insultos?, México, Océano.

Kabateк, J. (2014), “Tradiciones discursivas y cambio lingüístico”, Lexis, 29.2, pp. 151-177.

Lavob, W. (1972), Language in the Inner City, Filadelfia, University of Pennsylvania Press.

LARA, L. F. (1992), "Para la historia lingüística del pachuco", Anuario de Letras, XXX, pp. 75-88. 
LARA, L. F. (2011), "La definición lexicográfica del vocabulario de germanía y jergal”, en Memorias, México, El Colegio Nacional, pp. 159-167.

LARA, L. F. (2012), "Hacia una tipología de las tradiciones verbales populares", Nueva Revista de Filología Hispánica, LX, 1, pp. 51-60.

LARA, L. F. (2015), Temas del español contemporáneo. Cuatro conferencias en El Colegio Nacional, México, El Colegio de México.

Lope Blanch, J. M. (1989), Estudios de lingüística hispanoamericana, México, Universidad Nacional Autónoma de México.

MañaCH, J. (1955), Indagación del choteo, La Habana, Libro Cubano.

Mendoza, E. (2008), Balas de plata, México, Tusquets.

Mijares, M. (1985), Los relatos de costumbres, México, PROMEXA.

Monsiváis, C. (1988), Escenas de pudor y liviandad, México, Grijalbo.

Monsiváis, C. (1997), “"Ahí está el detalle»: el habla y el cine en México", recuperado el 15 de noviembre de 2015 en http://cvc.cervantes.es/obref/congresos/zacatecas/cine/ponencias/monsivais.htm

Narbona, A. (1991), "Sintaxis coloquial y análisis del discurso", Revista Española de Lingüística, 21, 2, pp. 187204.

Narbona, A. (1992), "Notas sobre sintaxis coloquial y realismo en la literatura narrativa española”, en José Antonio Bartol Hernández et al. (coords.), Estudios filo- 
lógicos en homenaje a Eugenio de Bustos Tovar, vol. 2, Salamanca, pp. 667-674.

Pérez Martínez, H. (1996), El hablar lapidario: ensayo de paremiología mexicana, Zamora, El Colegio de Michoacán.

Rivera, E. (2010), “Descripción de algunos de los procesos de construcción lingüística de los albures con formación No es lo mismo... que...", tesis para obtener el grado de Licenciado en Lengua y Literatura Hispánicas, Universidad Nacional Autónoma de México-Acatlán, recuperado el 3 de julio de 2016 en http://132.248.9.195/ ptd2010/enero/0653068/0653068_A1.pdf

Vigara Tauste, A.M. (1992), Morfosintaxis del español coloquial. Esbozo estilístico, Madrid, Gredos. 
